\title{
A VULNERABILIDADE DA ADOLESCENTE ÀS DOENÇAS SEXUALMENTE TRANSMISSÍVEIS: CONTRIBUIÇÕES PARA A PRÁTICA DA ENFERMAGEM
}

\section{Contributions to the practice of nursing: the vulnerability of adolescents to sexually transmitted diseases \\ La vulnerabilidad del adolescente a las enfermedades de transmisión sexual: contribuciones a la práctica de enfermería.}

\author{
Ana Cláudia Mateus Barreto ${ }^{1}$
}

Rosângela da Silva Santos ${ }^{2}$

\section{RESUMO}

Trata-se de uma pesquisa de natureza qualitativa, cujo método empregado foi a História de Vida. Teve por objeto de estudo a vulnerabilidade da adolescente à doença sexualmente transmissível (DST). Os objetivos foram: identificar a condição de vulnerabilidade da adolescente em atendimento em maternidade pública no Rio de Janeiro; descrever as estratégias adotadas por adolescentes para prevenção das doenças sexualmente transmissiveis; analisar, a partir da história de vida de adolescentes, sua condição de vulnerabilidade às doenças sexualmente transmissíveis. A partir da realização deste estudo, evidenciou-se que as adolescentes, ao conviverem em núcleos familiares não coesos, são menos resilientes e, consequentemente, mais vulneráveis a contrair uma DST. 0 estudo evidenciou a importância de os enfermeiros se apropriarem dos conceitos de vulnerabilidade e resiliência para se tornarem aptos a estimular e aumentar a autoestima das adolescentes, e diminuir a sua vulnerabilidade às DST.

Palavras-chave: Vulnerabilidade. Adolescente. Doenças Sexualmente Transmissíveis. Enfermagem. Pesquisa Qualitativa

\begin{abstract}
The present study is a research of qualitative nature. The method used was the Life History method. The main purpose of this research was to analyze the vulnerability of adolescents to sexually transmitted diseases (STD). The objectives were to identify the vulnerable conditions of adolescents under care at maternity wards of public hospitals in Rio de Janeiro and to describe the strategies adopted by adolescents to prevent sexually transmitted diseases. This was done by obtaining the life history of adolescents and analyzing their vulnerability to sexually transmitted diseases. According to this study, adolescents with unstable family backgrounds are less resilient, and therefore more vulnerable to being infected by sexually transmitted diseases. The study emphasizes the importance of nurses taking ownership of the concepts of vulnerability and resilience to be able to stimulate and enhance self-esteem in adolescents and reduce their vulnerability to sexually transmitted diseases.
\end{abstract}

keywords: Vulnerability. Adolescent. Sexually Transmitted Diseases. Nursing, Qualitative Research

\section{Resumen}

Se trata de una investigación de naturaleza cualitativa, cuyo método empleado fue los historias de Vida. Tuvo por objeto de estudio la vulnerabilidad del adolescente a las enfermedades sexualmente transmisibles (EST). Los objetivos fueron: identificar la condición de vulnerabilidad del adolescente que recibe atención en la maternidad pública en Río de Janeiro; describir las estrategias adoptadas por los adolescentes para la prevención de las enfermedades sexualmente transmisibles; analizar, a partir de la Historia de vida de adolescentes, su condición de vulnerabilidad a las enfermedades sexualmente transmisibles. A partir de la realización de este estudio, se evidenció que adolescentes al convivir en núcleos familiares sin cohesión, son menos resistentes, y consecuentemente, más vulnerables a contraer una enfermedad sexualmente transmisible. El estudio evidenció la importancia de que los enfermeros (as) se apropien de los conceptos de vulnerabilidad y resiliencia para estar aptos para estimular y aumentar la auto-estima de las adolescentes, y consecuentemente disminuir su vulnerabilidad a las enfermedades sexualmente transmisibles.

Palabras clave: Vulnerabilidad. Adolescente. Enfermedades de Transmisión Sexual. Enfermería. Investigación Cualitativa.

${ }^{1}$ Enfermeira. Mestre em Enfermagem pela EEAN, UFRJ. Professora Substituta do Departamento de Enfermagem Materno-Infantil e Psiquiátrica (MEP) da Escola de Enfermagem Aurora de Afonso Costa - EEAAC/UFF. Enfermeira da Maternidade. Brasil. E-mail: acmb@click21.com.br, 2Doutora em Enfermagem, Professora Titular em Estimulação Essencial do DEMI /EEAN/ UFRJ. Pesquisadora 1 C do CNPq / FAPERJ /UFRJ/ Núcleo de Pesquisa em Saúde da Criança (NUPESC) / Núcleo de Pesquisa em Saúde da Mulher (NUPESM) / EEAN/UFRJ. Brasil. E-mail: rosangelaufrj@gmail.com 


\section{INTRODUCÃO}

Esta pesquisa é um recorte da dissertação de mestrado de uma das autoras;" apresenta como objeto de estudo "a vulnerabilidade da adolescente à Doença Sexualmente Transmissível (DST)". A inquietação que deu origem a este estudo emergiu de sua prática profissional como enfermeira em uma maternidade municipal, da cidade do Rio de Janeiro, na qual desenvolve suas funções há nove anos.

Ao longo deste período, constatamos a alta incidência de filhos de mães adolescentes entre os recém-nascidos tratados para sífilis congênita. Presenciamos, também, casos de adolescentes portadoras de condiloma que, em algumas situações, necessitaram que seus filhos nascessem por cesariana devido ao grau de comprometimento do canal de parto. Observamos ainda recém-nascidos serem submetidos a tratamento para conjuntivite purulenta. Outro fato que chamou nossa atenção é que, vez por outra, adolescentes são internadas no setor após serem submetidas a wintercuretagem porque sofreram abortamento espontâneo o que, segundo o Ministério da Saúde, pode estar associado a uma DST não tratada² .

Uma outra inquietação que motivou a realização deste estudo foi o fato de os dados epidemiológicos existentes serem isolados, já que não existe prevalência das DST e somente a AIDS e a sífilis congênita são de notificação compulsória. A existência de uma DST traz consigo grande possibilidade de se adquirir o vírus HIV/AIDS.

No Brasil, a incidência de DST/AIDS tem crescido na população em geral, sendo o número de adolescentes contaminados também crescente. ${ }^{3} \mathrm{~A}$ precocidade nas relações sexuais, a multiplicidade de parceiros e a pouca utilização de preservativos, associada a uma maior liberdade sexual, são alguns dos fatores conhecidos que podem contribuir para aumentar a vulnerabilidade das adolescentes as DST.

Adotamos o conceito de vulnerabilidade de Ayres ${ }^{4}$, que considera a vulnerabilidade como a chance de exposição das pessoas ao adoecimento, resultando não somente em um conjunto de aspectos individuais, mas de fatores coletivos e contextuais, que acarretam aos indivíduos maior suscetibilidade e maior ou menor disponibilidade de recursos para se protegerem. Busca determinar uma síntese conceitual e prática das dimensões sociais, político - institucionais e comportamentais associadas às diferentes suscetibilidades de indivíduos e grupos populacionais. A vulnerabilidade é articulada em três eixos, a saber: Individual, Social e Programático. ${ }^{5}$

0 estudo teve por objetivos: identificar a condição de vulnerabilidade da adolescente, em atendimento em maternidade pública no Rio de Janeiro; descrever as estratégias adotadas por adolescente para prevenção das Doenças Sexualmente Transmissíveis; analisar a partir da história de vida de adolescentes sua condição de vulnerabilidade às Doenças Sexualmente transmissiveis.

A relevância deste estudo está pautada nas altas incidências mundiais das DST, principalmente em adolescentes, apesar de só existirem estudos isolados acerca da prevalência das DST. Esperamos que o resultado do estudo contribua para a educação em saúde da adolescente, propondo novos modelos assistenciais que contemplem um novo olhar em relação aos Direitos Sexuais e Reprodutivos das adolescentes. Este estudo fornecerá subsídios para o aprofundamento de debates e reflexões críticas tanto na graduação, quanto na pós-graduação lato e strictu sensu na área da saúde da criança e do adolescente.

\section{MÉTODO}

Trata-se de um estudo descritivo de natureza qualitativa, cujo método utilizado foi a História de Vida. Este método leva o pesquisador a conhecer a essência da história de vida de seus sujeitos a partir de suas próprias narrativas. Logo, consiste em dar aos sujeitos a oportunidade de relatar sua vida, tal e qual sua visão de mundo e de sua realidade. ${ }^{6}$

0 papel do pesquisador consiste em não invadir as particularidades da vida do sujeito, pois devemos respeitar, sob quaisquer circunstâncias, sua vontade de guardar algo para si mesmo.?

0 estudo foi realizado em uma maternidade municipal, da cidade do Rio de Janeiro. Sua escolha como campo para realização deste estudo justifica-se por esta unidade ser referência no atendimento à adolescente. Os sujeitos deste estudo foram 12 adolescentes atendidas no setor do Alojamento Conjunto, independente de serem gestantes, puérperas ou terem sofrido abortamento espontâneo.

Para atender as exigências estabelecidas pela Resolução n. ${ }^{0196 / 96}$ do Conselho Nacional de Saúde que dispõe sobre as Diretrizes e Normas Regulamentares de Pesquisa Envolvendo Seres Humanos ${ }^{8}$, o presente estudo foi aprovado no Comitê de Ética e Pesquisa da Secretaria Municipal de Saúde sem exigências em janeiro de 2008 sob o n ${ }^{\circ}$ CAAE0275.0.314.000-08.

Os sujeitos do estudo foram adolescentes que aceitaram participar do estudo e cujas mães e/ou responsáveis autorizaram que elas fornecessem os depoimentos. Ambas foram devidamente esclarecidas, por meio de leitura prévia e, posteriormente, assinaram o Termo de Consentimento Livre e Esclarecido (TCLE). Os relatos de vida das depoentes foram gravados em gravador digital e as transcrições foram realizadas imediatamente após como preconizado por Daniel Bertaux. ${ }^{9}$ Os relatos foram obtidos a partir de uma entrevista aberta com a seguinte questão norteadora: "Fale-me a respeito de sua vida que tenha relação com sua experiência sexual".

A fim de garantir o sigilo e o anonimato dos sujeitos da pesquisa, as adolescentes foram identificadas com o nome de fadas, os quais foram escolhidos pelas pesquisadoras, pois a intenção foi identificá-las de maneira análoga com seus momentos de vida. Assim foi que optamos pela identificação simbólica do momento mágico vivenciado por elas no período da adolescência. 
0 processo analítico adotado neste estudo foi a análise temática. Concomitante às transcrições das entrevistas, iniciase análise dos relatos, pois este procedimento facilita a avaliação do procedimento metodológico, possibilitando ao pesquisador realizar ajustes e redirecionar seu caminhar caso seja necessário ${ }^{10}$.

A fim de realizar a análise do material transcrito, iniciamos a leitura flutuante com leituras sucessivas das entrevistas visando impregnação do discurso. À medida que realizávamos as leituras, concomitantemente, realizamos a técnica de marcação com hidrocor colorida das unidades temáticas. Do movimento de codificação emergiram 63 unidades temáticas. A seguir realizamos a recodificação, que foi a nova leitura das entrevistas, comparando as unidades temáticas, buscando a possibilidade de descobrir temas que convergiam ou se afastavam e novos temas, de onde emergiram as duas grandes categorias de análise. Apresenta-se neste artigo uma das categorias de análise.

\section{RESULTADOS E DISCUSSÃO}

Os resultados descritos a seguir retratam parcialmente a categoria de análise intitulada: A Sexualidade da Adolescente e sua Vulnerabilidade às DST, por meio da qual nos foi possível notar que as entrevistadas têm dúvidas, desconhecimentos e deficiência de informação em relação ao tema sexualidade. Sabemos que essa temática é ainda muito complexa de se lidar, visto que, até hoje, envolve preconceitos e tabus.

[...] já pensou quando [...] eu tiver minha primeira relação? "Ela: "Ih [...] não fala comigo sobre isso não [...] ela já falou isso comigo, deixa [...] espera mais um pouquinho [...] não estou preparada pra ouvir isso. Ela falava isso [...] então, eu achava chato isso dela, só que eu não entendia que ela não estava preparada [...] pra conversar com a filha adolescente [...] (Fada Benfana, 17 anos).

No depoimento de fada Benfana, evidencia-se a dificuldade de sua mãe em conversar com ela acerca da iniciação sexual, visto que "[...] muitos pais encontram dificuldade em conversar sobre sexo com suas (seus) filhas (os), pois foram educados em outra época, sentem dificuldade em agir de maneira diferente, apesar de, muitas vezes, acharem que a educação que receberam não foi boa para eles e desejarem que houvesse acontecido de modo diferente [...]".11

Em razão das dúvidas encontradas pelas adolescentes entrevistadas, várias foram as fontes de informações que as mesmas utilizaram buscando informações acerca de sexualidade, como podemos evidenciar no relato a seguir ao consultar uma professora:
[...] A gente se reúne [...] aí a gente chega nela [...] e pede a ela [...] pra conversar com a gente sobre o negócio do uso da camisinha [...] mas [...] ela fala: [...] Não, depois eu faço isso, depois eu converso, e nunca [...] nunca, nunca conversa com a gente [...] nunca escreve nada [...] nunca fala [...] (Fada Aril, 13 anos).

A dificuldade de pais e educadores em tratar do tema sexualidade possivelmente reside no fato de acreditarem que, uma vez mantidos diálogos acerca de tal temática, poderiam estar incentivando os adolescentes à prática sexual, acrescido o fato de que, para tratarmos abertamente do tema em questão, faz-se necessário, primeiramente, trabalharmos adequadamente nossa própria sexualidade, uma vez que também recebemos de nossos pais educação carregada de preconceito e tabu. Ficou claro o despreparo e o pouco comprometimento de alguns professores, já que a professora em questão se esquivava de tal tarefa. Depreende-se daí que a omissão dos profissionais do setor educacional, neste caso, potencializa a vulnerabilidade social das adolescentes. 0 episódio indica lacunas no plano programático do sistema de ensino e a falta de ações protetoras. No caso da fada Aril, portanto, pode-se dizer que sua gestação foi consequência de falhas nos planos individual, social e programático da vulnerabilidade.

A gênese desta limitação pode ter sua origem não só nos próprios tabus e preconceitos presentes na formação recebida pelas docentes, mas na qualidade de sua capacitação. Um profissional despreparado não consegue atender os anseios da adolescente. Enquanto se questiona a quem efetivamente cabe esta responsabilidade e não se aprimora a qualidade das informações prestadas às adolescentes, elas continuam vulneráveis tanto no plano individual quanto no social e no programático.

A realização deste estudo possibilitou-nos evidenciar que uma das condutas empregadas pela(o) adolescente, visando firmar sua autonomia, é a primeira relação sexual. Nessa experiência está embutida a perda da virgindade. No tempo das avós de nossas depoentes, a virgindade era bastante valorizada e algo a ser preservado até o matrimônio. A preservação da virgindade foi bastante influenciada por aspectos religiosos, principalmente à luz do cristianismo, no qual a castidade está intimamente associada à imagem da virgem imaculada. Contudo, evidenciamos a não valorização da virgindade em diversos relatos das entrevistadas, como exemplificado a seguir:

[...] Ah, no início eu tinha muita curiosidade [...] antes de conhecer alguém [...] eu tinha muita curiosidade [...] Aí, eu sempre tentava com as pessoas [...] com os garotos que eu saía, quando eu era mais nova [...] Mas eu nunca conseguia [...] tentei umas duas vezes ou três vezes. [...] não conseguia que doía muito [...] (Fada Mab, 19 anos). 
A perda da virgindade é considerada como um rito de passagem, pois a partir deste momento, a menina deixará de fazer parte do mundo infantil para compor o mundo dos adultos agora na condição de mulher. E se neste momento a menina vier a engravidar, esta gestação será a afirmação do exercício de sua vida sexual "[...] a adolescente vive a ambiguidade de ser então sexualmente adulta e em situações de dependência nas dimensões econômicas e familiares, entre outras [...]".12

Ressalta-se que as adolescentes passaram a vivenciar sua sexualidade de maneira mais liberal a partir da revolução sexual e do movimento "hippie" dos anos 60/70. Outro fator preponderante nesta conquista foi o advento da pílula anticoncepcional. A partir dela, a mulher passou a manter suas relações sexuais de modo mais livre, sem ter que se preocupar com uma gravidez. A mulher, assim, conquistou o direito de sentir prazer, algo que, anteriormente ao advento da pílula anticoncepcional, só era facultado aos homens " [...] o caráter subjetivo da construção da sexualidade expõe à importância das relações de poder entre os diversos sujeitos sociais. A questão de gênero é, por conseguinte, uma das mais fundamentais situações de relação de poder que necessita ser considerada na discussão da vulnerabilidade [...]". ${ }^{4}$

Muito embora a revolução sexual tenha proporcionado à mulher o direito de sentir prazer, ela ainda não conseguiu desvencilhar-se até hoje, por diversas razões, entre elas as de ordem cultural, da responsabilidade pela prevenção da gravidez que ainda recai sobre si. Este paradigma necessita ser quebrado, pois esta responsabilidade não pode continuar cabendo tão somente à mulher, mas também ao homem, como ficou evidenciado nos depoimentos das adolescentes:

[...] E ele ainda não gosta de usar camisinha, $e$ agora que eu fiz "coletagem", eu acho que agora que eu tenho que ter bastante cuidado, porque a qualquer hora, porque meu útero tá todo limpinho [...] a qualquer hora [...] aí é mais fácil ainda de eu pegar uma gravidez, então agora que eu vou ter que sentar chegar, sentar e conversar com ele [...]. Oh, tem que usar a camisinha [...] enquanto eu não estou tomando remédio [...] pra que não aconteça isso de novo, porque ainda tá cedo [...] assim a gente tem que esperar um pouco, e ele vai ter que aceitar, se ele não aceitar [...] ele vai ter que ficar sozinho [...] vai ter que procurar outra agora [...] (Fada Arifa, 18 anos).

0 paradigma da responsabilidade quanto à prevenção de uma gravidez cabe historicamente ao sexo feminino. Essa imposição deve mudar, e os cuidados devem ser compartilhados igualitariamente com o sexo masculino. No relato de fada Arifa, evidencia-se que ela já tem um posicionamento favorável quanto à divisão desta responsabilidade "[...] se, por um lado, a utilização de contraceptivos orais possibilitou à adolescente 0 exercício mais livre de sua sexualidade e facultou-lhe o direito de decidir quando e quantos filhos desejaria ter, por outro lado, interferiu de maneira negativa no processo de negociação sexual com seu parceiro, já que, predominantemente, responsabilizoua pela contracepção [..."1'3.

Desde a década de 80 nossos adolescentes vivenciam sua vida amorosa de um modo bastante diferente da vivenciada pelas gerações anteriores, já que hoje existe uma diversidade de formas de relacionamentos que deram origem a novos padrões de comportamentos. Na atualidade, os adolescentes se conhecem previamente num namoro sem compromisso, denominado "ficar", o qual pode durar apenas uma noite, algumas semanas ou evoluir para um compromisso mais sério. Identificamos este tipo de relacionamento nos depoimentos de várias depoentes, dos quais destacamos os relatos das fadas Aril e Mab.

[...] A gente ficava. [...] sei lá, a gente conversava, brincava [...] ai depois que a gente começou [...] a "ficar" [...] ele me chamava, conversava. [...] foi assim [...] (Fada Aril, 13 anos).

[...] Quê, éruim, eu vouécasar [...] ficar nada, se sai uma noite acaba ficando [...]. Ah, não tem essa, a gente acaba namorando, beija aqui, esquenta ali, por mais que você se controla, acaba acontecendo [...] (Fada Anna, 19 anos).

Este novo tipo de relacionamento proporciona a possibilidade de múltiplos parceiros até mesmo em uma mesma noite, sem que nenhum deles implique compromisso mais sério. Afinal de contas, para que se "fique" com alguém basta que haja desejo. A prática do "ficar" traz em seu bojo a multiplicidade de parceiros; "[...] este tipo de relacionamento pode suceder de um desejo claro e explíito de um ou de ambos, assim como de forma impulsiva, como descarga ou como uma vontade superficial, a qual muitas vezes conta com o incentivo de amigos em situações específicas, tais como as festas e encontros [...]" ${ }^{14}$

Foi possível evidenciar, por meio dos relatos de vida das entrevistadas, que alguns fatores continuam a ser preponderantemente responsáveis por manter a vulnerabilidade destas adolescentes. Além da precocidade de suas vivências sexuais, destacamos que a multiplicidade de parceiros também se constitui em um fator importante.

Devemos considerar também que uma vez aflorado o desejo, o uso do preservativo se dá na maioria das vezes de maneira não assertiva. No período da adolescência, o indivíduo normalmente age por impulso, impelido pela sensação de invulnerabilidade muitas vezes estimulada pela utilização de bebidas alcoólicas e/ou drogas. As fadas Anna e Aine relataram ter feito uso de bebida alcoólica. Esse componente torna as adolescentes mais vulneráveis a contrair uma DST.

[...] o filho dele começou a ir lá em casa e beber e aía gente foie começamos a namorar. Começamos 
com 11, com 12, aía gente foi e [...] entendeu! Aí com 13 engravidei [...] tive a minha filha com 14 [...] e é isso aí, é complicado [...] (Fada Anna, 19 anos.)

[...] eu conheci ele num dia normal, aí marcamos pra sair numa noite. Aí eu bebi, ele bebeu, aíjá era, foi aí que a neném nasceu [...] (Fada Aine, 19 anos).

0 uso de bebidas alcoólicas na adolescência é responsável por aumentar a vulnerabilidade de adolescentes e está muitas vezes associado ao uso concomitante de drogas. Diversas de nossas depoentes confirmaram o consumo de bebidas, possivelmente porque o álcool deixa seus usuários desinibidos. Ao longo dos depoimentos, no entanto, nenhuma depoente admitiu fazer uso de outras drogas. 0 resultado de um estudo realizado com 251 adolescentes indicou uma multiplicidade de fatores de risco às DST. Dentre às variáveis associadas as DST, 0 uso de bebidas alcoólicas e/ou drogas foi apontado.. ${ }^{15}$

Nossas depoentes também podem ser consideradas vulneráveis no plano social, visto que não têm poder de negociação com seus parceiros. Isso as torna mais vulneráveis ao gênero masculino no que tange à utilização do preservativo masculino. Apesar das mudanças ocorridas ao longo dos últimos 40 anos, por conta da já citada revolução sexual, ainda predomina uma forte assimetria de gênero entre as meninas que não se protegem e se expõem às DST. A submissão destas adolescentes é resultado, assim, dos valores culturais oriundos da influência materna.

Das adolescentes entrevistadas, $50 \%$ relataram que seus companheiros eram contrários à utilização do preservativo. Este é mais um fator que apontamos como responsável pelo aumento da vulnerabilidade das adolescentes deste estudo às DST.

[...] eles falavam: "ah, não é bom [...] transar com camisinha [...]. Eu ia muito pela cabeça deles, eu era muito criança ainda [...] agora, depois de grande, eu [...] me previno mais[...]

(Fada Iris, 17 anos).

A dificuldade de negociar o uso do preservativo não é encontrada só entre as adolescentes, mas também é vivenciada pela mulher adulta de um modo geral. Solicitar simplesmente seu uso pode trazer o desconfor to da desconfiança, aumentando, desta forma, a vulnerabilidade individual do gênero feminino. As fadas Arifa e Iris estavam expostas não só à vulnerabilidade individual, pela não utilização de preservativos, mas também à vulnerabilidade social por questões diretamente relacionadas ao gênero masculino, no que diz respeito à dificuldade de negociação, conforme demonstraram seus relatos. Uma das questões mais críticas para as adolescentes em relação à prevenção é a negociação com o parceiro sobre a utilização de preservativos. Ao insistir (ou simplesmente pedir) para que seus parceiros utilizem o preservativo, algumas adolescentes receiam estar colocando em risco sua relação amorosa ou mesmo receiam perder seu parceiro. Perdendo seus parceiros, elas podem estar não somente abrindo mão de uma relação que lhes dá status e apoio emocional, mas também suporte financeiro. ${ }^{13}$

A resistência à utilização do preservativo pode trazer como consequência a contaminação por uma DST ou uma gravidez. No caso das depoentes, todas se expuseram ao risco, já que estavam ali por conta de gestação ou processo de abortamento. Das doze adolescentes entrevistadas, três abortaram espontaneamente, mas apenas uma relatou o desejo de ter um filho naquele momento de sua vida. 0 desejo do parceiro de ter um filho, entre outras razões, motivou algumas das adolescentes entrevistadas a levarem a gestação até o final.

[...] eu não sabia [...] tava querendo [...] mas não sabia que eu tinha conseguido por causa do cisto que eu tinha no ovário [...] minha gravidez foi uma maravilha, graças a Deus [...] (Fada Áurea, 18 anos.)

[...] ele chegou pra mim. [...] poxa Fylgiar, eu quero ficar com você mesmo, eu acho você a pessoa certa, [...] vamos ter esse filho [...] (Fada Fylgiar, 18 anos).

0 desejo pela maternidade ficou claro durante o depoimento prestado pela fada Áurea. Ela foi a única que levou a gravidez adiante de modo consciente. Já no depoimento de Fylgiar, ficou evidente que ela foi induzida por seu companheiro a assumir a maternidade naquele momento de sua vida e contra suas perspectivas futuras. Ainda sobre a fada Fylgiar, é possível afirmar que sua gestação foi produto de sua vulnerabilidade não só individual, já que ela não lançou mão de ações protegidas e protetoras, mas também de uma vulnerabilidade social. Esta última tem relação direta com o desejo de seu parceiro e é programática, pois a adolescente em questão não teve nenhuma orientação por parte dos serviços visando à prevenção tanto de uma DST quanto de uma gestação.

0 aumento da taxa de fecundidade entre adolescentes e jovens, assim como o número de óbitos maternos nesta faixa etária, vem a ser um forte indicador de que as políticas públicas de contracepção, planejamento familiar e atenção pré-natal não têm se adequado ou atendido às necessidades específicas deste segmento populacional. ${ }^{16}$

Este estudo apontou que das 12 adolescentes entrevistadas, $66,67 \%$ (8) realizaram o pré-natal, das quais apenas 37,5\% (3) submeteram-se a um número de consultas superior ao preconizado pelo Ministério da Saúde, que é de, no mínimo, seis consultas. Isso nos leva a crer que elas podem ter iniciado o pré-natal no tempo certo. Já o percentual de adolescentes que realizaram o pré-natal com número inferior de consultas foi de $62,5 \%$ (5). Por outro lado, 33,33\% (4) das investigadas não fizeram pré-natal. A partir do percentual de adolescentes que não realizou o pré-natal e aquelas que 
não realizaram o número mínimo de consultas preconizadas, é possível concluir que a captação das adolescentes para o prénatal deve ser revista, já que esta é uma das poucas razões que ainda aproxima as adolescentes dos serviços de saúde.

Cabe destacar, contudo, que, por vezes, a adolescente inicia seu pré-natal tardiamente porque demora a anunciar sua gestação à família por medo, vergonha ou até mesmo desconhecimento, uma vez que, nesta fase da vida, a adolescente ainda não tem ciclos menstruais regulares.

Por conta da dificuldade no atendimento, da utilização incorreta dos contraceptivos orais, da dificuldade de negociação com seus parceiros, da pouca utilização de preservativos (usados para prevenir apenas a gravidez) e até mesmo pela má fé do parceiro de uma das adolescentes entrevistadas, $41,67 \%$ (5) das adolescentes revelaram que em algum momento de suas vivências sexuais já haviam lançado mão do recurso da "pílula do dia seguinte".

[...] eu não procurei um ginecologista, pra "procurar uma orientação de [...] anticoncepcional [...] o único método contraceptivo que eu usava era realmente o preservativo. [...] fora esse [...] e nas poucas vezes que eu usava. Aí, algumas vezes que eu ficava em dúvida, tomava a pilula do dia seguinte [...] (Fada Mab, 19 anos).

[...] eu nunca gostei de usar camisinha [...] nunca gostei mesmo [...] era muito raro porque eu não gostava [...] você não precisa tomar remédio [...] porque eu fiz vasectomia [...] então não tem necessidade de você tomar remédio nenhum. Mas aí eu comecei a desconfiar [...] após 5 meses eu comecei a desconfiar, que toda vez que a gente tinha relação, ele ia na farmácia e comprava pílula do dia seguinte pra mim, e homem que fez vasectomia não tem preocupação com isso[...] (Fada Deive, 17 anos).

A "pílula do dia seguinte" pode ser facilmente comprada em qualquer drogaria da cidade do Rio de Janeiro, bastando, para tanto, um simples telefonema. A farta comercialização do medicamento pode ser constatada principalmente nos finais de semana nas farmácias que ficam abertas 24 horas. A pílula vem sendo usada de maneira incorreta porque, ao substituir o preservativo, com a finalidade de evitar uma gravidez indesejada, deixa a usuária vulnerável às chamadas DST.

0 afastamento da população adolescente dos serviços de saúde, a deficiência das orientações prestadas e a prevenção às DST realizada de modo incorreto foram responsáveis pelo diagnóstico de sífilis em duas das adolescentes entrevistadas. No entanto, o diagnóstico da DST só foi possível, em ambos os casos, devido à gestação das referidas adolescentes. Do contrário, elas não saberiam que eram portadoras de sífilis, visto que muitas das DST se manifestam de maneira assintomática.

Cabe destacar que, no decorrer dos relatos de todas as adolescentes, ao mencionarem as DST, elas foram unânimes em citar a AIDS como uma doença sexualmente transmissível, como podemos evidenciar no relato a seguir:

[...] Conhecer, eu não conheço, eu sei que tem a AIDS, a sífilis [...] mas eu não conheço todas não [...] Na verdade, eu não sei nada sobre elas [...] se previne com preservativos [...] mas [...] conhecer, eu não conheço não. Por que [...] a AIDS não não tem cura, eu tinha medo de pegar essa doença, [...] uma doença que eu saiba que não vai nunca ficar curada e eu tinha medo das pessoas saberem que eu tava com aquela doença, sei lá [...] se afastar de mim, com medo de alguma coisa, porque tem muitas pessoas que tem preconceito [...] esse é o meu medo [...] (Fada Daisy, 16 anos).

Fada Daisy foi internada na unidade hospitalar, por uma ameaça de parto prematuro e também fez novo exame VDRL. 0 resultado, 1:4, aparece no prontuário médico com 0 diagnóstico de possível cicatriz sorológica. Ao longo de seu depoimento, o mais extenso de todos, a adolescente, em nenhum momento, fez menção à sua contaminação pela sífilis. Ela deixou claro diversas vezes que não gosta de conversar "sobre esses assuntos".

Ao se referir às DST, fada Daisy deixou entrever certo constrangimento, possivelmente por saber que seu exame VDRL fôra positivo e a levara a se submeter a tratamento para sífilis. Ela demonstrou saber que a sífilis é uma DST, mas não admitiu em nenhum momento de seu depoimento ser portadora desta doença. A exemplo da maioria das adolescentes entrevistadas, Daisy referiu ter receio de contrair a AIDS por saber que a doença não tem cura. Seu receio se devia também ao fato de "as pessoas terem preconceito em relação à AIDS".

Sabemos, contudo, que o preconceito mencionado por ela não existe só em relação à AIDS, mas a todas às DST, e que estas doenças sempre estiveram associadas, de um modo geral, à promiscuidade e às "mulheres de vida fácil". Também merece destaque sua visível dificuldade em abordar a temática. Essa fuga seguramente está relacionada à suas raízes culturais oriundas da educação que recebeu na infância.

0 diagnóstico de sífilis em duas adolescentes entrevistadas só foi possível graças ao protocolo do Ministério da Saúde que preconiza, com vistas à prevenção e diagnóstico da sífilis materna, a realização do teste VDRL na primeira consulta do pré-natal. A ida da gestante ao médico deve ocorrer preferencialmente no $1^{\circ}$ trimestre da gravidez. Outro exame deve ser realizado no início do terceiro trimestre ( $28^{\mathrm{a}}$ semana) da gravidez. Os casos diagnosticados em gestantes devem ser imediatamente tratados juntamente com seus parceiros. 0 
tratamento é considerado adequado quando está adequado ao estágio da doença, é realizado com penicilina e é concluído. É necessário ainda que o referido tratamento seja finalizado pelo menos 30 dias antes do parto, concomitante ao tratamento dos parceiros. ${ }^{17}$

0 Ministério da Saúde realizou um estudo em seis capitais brasileiras com a finalidade de fomentar o conhecimento da

\section{CONSIDERACÕES FINAIS}

A partir da realização deste estudo, evidenciamos que a vulnerabilidade das adolescentes as DST é algo muito mais complexo do que simplesmente a utilização do preservativo, pois a este hábito estão atreladas questões de ordem sociais, culturais e individuais. A realização desta pesquisa, no entanto, nos possibilitou conhecer um pouco mais de nossa clientela adolescente. É com base nesse conhecimento, acumulado a partir das histórias de vida narradas, que iremos adequar e melhorar o cuidado prestado a essa clientela, respeitando seu contexto social e cultural.

Os subsídios aqui gerados podem ser aproveitados não só no planejamento da assistência, mas também na formulação de novas políticas públicas de saúde voltadas para a área da adolescência e até mesmo na reformulação das já existentes.

À medida que o estudo foi sendo desenvolvido, percebemos que a vulnerabilidade individual destas adolescentes é consequência não só da falta de medidas protegidas e protetoras, mas de algo muito mais complexo que envolve a vulnerabilidade individual de cada uma delas e também tem ligação direta com os planos social e programático.

A realização deste estudo vem corroborar as evidências levantadas em outros estudos da mesma natureza que identificaram a vulnerabilidade das adolescentes às DST, uma vez que nos foi possível identificar a condição de vulnerabilidade das adolescentes a partir de suas histórias de vida. Este estudo também nos possibilitou observar que as adolescentes não adotavam estratégias de prevenção às DST.

A pesquisa mostrou também que as adolescentes não buscam os serviços de saúde visando à prevenção para 0 realidade brasileira quanto às DST no contexto da saúde pública no país. 0 universo pesquisado envolveu 3.303 gestantes. Deste total, 33,1\% eram menores de 20 anos. Dos resultados obtidos, as maiores prevalências dos casos de gonorreia, clamídia e HPV ocorreram na população adolescente, na faixa etária de 10 a 19 anos, sendo a maior prevalência de sífilis em mulheres acima de 40 anos. $^{18}$

exercício pleno de sua sexualidade. Na verdade, aquelas que procuraram os serviços de saúde ou planejamento familiar o fizeram com o intuito de prevenir somente uma futura gravidez. Mais que planejar, a adolescente necessita de serviços que the ofereçam a possibilidade do exercício pleno e protegido de sua sexualidade, ou seja, que lhe garantam seus direitos sexuais e reprodutivos.

Quando iniciamos este estudo, movidas pela inquietação da vulnerabilidade das adolescentes às DST, não imaginávamos a magnitude desta vulnerabilidade. Ao concluir este estudo, evidenciamos que as adolescentes têm algumas informações sobre as DST, entretanto estas informações são ainda bastante incipientes. Na verdade, as adolescentes, assim como grande parte da população, só mencionaram a AIDS como uma DST. Afinal de contas, o HIV, no imaginário popular, é o grande vilão responsável pela morte de seus portadores. Quanto às demais DST, as adolescentes do estudo as desconheciam ou tinham conhecimento delas de maneira muito superficial, sem levar em conta a dimensão dos agravos que estas doenças podem desencadear a médio e longo prazo.

Quanto aos programas de saúde voltados para a saúde da adolescência, sabemos que existem. Temos consciência de que, por meio de projetos, levantamentos e pesquisa, muitos esforços são implementados para melhorar a qualidade de vida a nossos adolescentes. Os depoimentos colhidos, no entanto, indicam que ainda existem falhas estruturais nestas iniciativas. As lacunas persistem quanto à capacitação dos profissionais de saúde e da área educacional no que diz respeito à sexualidade da adolescente e à prevenção das DST.

\section{REFERÊNCIAS}

1. Barreto ACM. A sexualidade da adolescente e sua vulnerabilidade às doenças sexualmente transmissíveis: contribuições para o cuidado de enfermagem. [dissertação de mestrado]. Rio de Janeiro (RJ): Escola de Enfermagem Anna Nery/ UFRJ; 2008.

2. Ministério da Saúde (BR). Manual de Controle das Doenças Sexualmente Transmissíveis. Secretaria de Vigilância em Saúde. Programa Nacional de DST e AIDS. Brasília (DF): 2005.140 p.

3. Codes JS, Cohen DA, Melo NA, Teixeira GG, Leal AS, Silva TJ, et al . Deteç̧ão de doenças sexualmente transmissíveis em ambientes clínicos e não clínicos na Cidade de Salvador, Bahia, Brasil. Cad Saude Publica [periódico na Internet]. 2006 fev [citado 21 out 2007 ]; 22(2): 325-34. Disponível em: http://www.scielosp.org/scielo.php? script $=s c i$ arttext \& pid $=S 0102-$ $311 \times 2006000200010 \& \operatorname{lng}=p t$. doi: $10.1590 /$ S0102-311X 2006000200010.

4. Ayres JRCM, Freitas AC, Santos MAS, Saletti FHC, França JI. Adolescência e AIDS: avaliação de uma experiência de educação preventiva entre pares. Interface (Botucatu) [periódico na Internet]; 2003 fev [citado 21 out 2007]; 7(12): 123-38. Disponível em: h t t p : / / w w w. s c i e l o . b r / scielo.php?script=sci_arttext\&pid=\$141432832003000100009 \&lng=pt. doi: 10.1590/\$1414-32832003000100009.

5. Ayres JRCM. 0 jovem que buscamos e o encontro que queremos ser: a vulnerabilidade como eixo de avaliação de ações preventivas 
do abuso de drogas, DST e AIDS entre crianças e adolescentes. In: Tozzi D, Santos NL, Amaro CM, Almeida E, Silva EJ, Pereira M.L, organizadores. Papel da educação na ação preventiva ao abuso de drogas e às DST/AIDS. São Paulo (SP): Fundação para 0 Desenvolvimento da Educação; 1996 a. p. 15-24. Série Idéias, 29.

6. Souza JG, Lima JM, Santos RS. Alcoolismo feminino: subsídios para prática profissional da enfermagem. Esc Anna Nery Rev Enferm 2008 dez; 12(4): 622-29.

7. Bertaux D. Los relatos de vida: perspectiva etnosociológico. Barcelona(ES): Ed Bellaterra; 2005.144 p.

8. Resolução n 196, de 10 de outubro de 1996. Diretrizes e normas regulamentadoras de pesquisas envolvendo seres humanos. Inf Epidemiol SUS 1996; 5 (2 supl 3): 13-41.

9. Bertaux D. L'approche biographique: sa validité metthodologique, ses potentialities. Cahiers Internationaux de Socioalogie 1980; LXIX: 197-225.

10. Spindola T, Santos RS. Trabalhando com a história de vida: percalços de uma pesquisa. Rev Esc Enferm USP 2003; 37(2): 119226.

11.Suplicy M. Sexo para adolescentes: amor, puberdade, masturbação, homossexualidade, anticoncepção, DST/AIDS, drogas. São Paulo (SP): FTD; 1998. 160 p.
12. Abramovay M, Castro MG, Silva LB. Juventude e sexualidade. Brasília (DF) UNESCO Brasil; 2004. 426p.

13. Sanches KRB. A AIDS e as mulheres jovens: uma questão de vulnerabilidade. Rio de Janeiro. [tese de doutorado]. Rio de Janeiro (RJ): Escola Nacional de Saúde Pública/ Fiocruz; 1999. 153p.

14. Matos M, Féres-Carneiro T, Jablonski B. Adolescência e relações amorosas: um estudo sobre jovens das camadas populares cariocas. Interação em Psicologia 2005; 9(1): 21-33.

15. Taquette SR, Andrade RB, Vilhena MM, Paula MC. A relação entre as características sociais e comportamentais da adolescente e as doenças sexualmente transmissíveis. Rev Assoc Med Bras 2005; 51 (3): 149 52.

16. Ministério da Saúde (BR). Secretaria de Atenção à Saúde. Departamento de Ações Programáticas Estratégicas. Marco teórico e referencial: saúde sexual e saúde reprodutiva de adolescentes e jovens. Brasília (DF); 2006.56 p.

17 Ministério da Saúde (BR). PN-DST/AIDS. Estimativas de algumas DST na população ativa no Brasil. [on-line] Brasília (DF); 2003. Disponivel em: www.aids.gov. br.

18 Ministério da Saúde (BR). Secretaria de Vigilância em Saúde. Programa Nacional de DST e AIDS. Prevalência e freqüências relativas de Doenças Sexualmente Transmissíveis-DST em populações selecionadas de seis capitais brasileiras, 2005. Brasília (DF); 2008. $224 p$ 